\title{
The Global Financial Crisis, Inflation Rate And Stock Market Returns In Kenya
}

\author{
Dr. Donald A. Otieno \\ Dr. Rose W. Ngugi
}

School of Economics, University of Nairobi, Kenya

Professor Nelson H. W.Wawire

School of Economics, Kenyatta University, Kenya

doi: 10.19044/esj.2017.v13n19p191 URL:http://dx.doi.org/10.19044/esj.2017.v13n19p191

\begin{abstract}
The moderating effect of events such as the 2008 Global Financial Crisis (GFC) on the relation between stock market returns and macroeconomic variables has attracted very little attention. This study investigates the extent to which the 2008 GFC moderated the relationship between inflation rate and stock market returns. The study uses month-onmonth inflation rate and year-on-year inflation rate from 1st January 1993 to 31st December 2015 and divides the sample data into pre-crisis period (from 1st January 1993 to 31st December 2007); crisis period (from 1st January 2008 to 30th June 2009); and post-crisis period (from 1st July 2009 to 31st December 2015). It uses a product-term regression model instead of the most widely applied additive regression model. Results indicate that a unit increase in the both measures of inflation rate had significant depressing effects on stock market returns after the crisis compared to before the crisis. Likewise, the results reveal that average stock market returns were significantly higher after the crisis compared to before the crisis at low rather than medium or high values of the two measures of inflation rate. These results suggest that the Kenyan stock market is highly sensitive to variations in inflation rate, especially as it emerges from a financial or political turmoil. This study is empirically innovative in the sense that it is the first to examine the moderating effect of the 2008 GFC on the relation between inflation rate and stock market returns in Kenya using a product-term model.
\end{abstract}

Keywords: Stock returns, Inflation rate, GFC, Product-term models

\section{Introduction}

Stock market returns provide useful signals regarding the future state of the economy, including the economic and financial status (Hamrita \& 
Trifi, 2011). Specifically, stock market returns drive the allocation of resources across all sectors of the economy. Their stochastic behaviour also provides information concerning market expectations and risk attitudes of investors in the market. Additionally, even though macroeconomists, financial economists and actors in the financial market use stock market indices to understand trends in the economy, describe stock markets and compare returns on specific investments (Hautcoeur, 2011), stock market returns are more preferred because they provide traders and investors with a scale-free summary of the ever rapid inflow of information into the stock market (Lo, Campbell \& Mackinlay, 1997). Equally, given their more attractive statistical properties (Lo, Campbell \& Mackinlay, 1997), stock market returns are useful to policymakers, researchers and stock market participants keen on making various forecasts, developing regulatory rules, constructing portfolio strategies or determining implications of policy. On the whole, understanding the trends of stock market returns is important for effective evaluation of the events in the financial market and tracking of the evolution of the economy. Nonetheless, stock market returns are systematically influenced by various types of information which arrives randomly to the stock market. A key type of such influential information is news regarding the evolution of inflation rate (Azar, 2015; Chen, Roll \& Ross, 1986; Demirhan, 2016).

Inflation is a major concern to investors because they expect to be compensated in terms of higher stock market returns to maintain their real returns (Fisher, 1930). This suggests that if the stock market is efficient, then investors expect nominal stock market returns to move on a one-to-one basis with expected inflation rate (in the strictest interpretation of Fisher Effect). However, since expected inflation rate is not observable, actual inflation rate is often a reasonable proxy, based on the theory of rational expectations (Rushdi et al., 2012). On the other hand, inflation poses a serious threat to long-term investors since it erodes the returns of financial assets, including stock market returns, by undermining real economic activity (Fama, 1981). This can in turn result into a rise in prevailing interest rates and depress overall economic growth. Furthermore, stock market returns often reflect valuation of cash flows over long horizons into the future (Alagidede \& Panagiotidis, 2010). Consequently, monthly stock market returns are likely to have stronger relationships with changes in inflation rate projected many months into the future (i.e. year-on-year inflation rate) rather than with changes in current month's inflation rate (i.e. month-on-month inflation rate).

But the influence of inflation rate on stock market returns is likely to be moderated by external events, especially shocks from events such as the 2008 Global Financial Crisis (Amaefula \& Asare, 2013; Kganyago \& 
Gumbo, 2015). This is because shocks from such events can have direct depressing effects on the entire economy, including the stock market (Birmingham, 2012; Elton et al., 2011). However, very little attention has been paid to this moderating effect as majority of existing studies mainly focus on the main effects models (or additive models) (Ouma \& Muriu, 2014; Kirui, Wawire \& Onono, 2014; Kumar \& Puja, 2012; Razzaque \& Olga, 2013). It is against this backdrop that this study was designed. The primary goal of the study was to examine the relationship between inflation rate and stock market returns within the context of a product-term regression model.

Consistent with the research problem, this study sought to address the following research questions: To what extent could the events such as the 2008 GFC have moderated the influence of inflation rate on stock market returns in Kenya? In other words, to what extent did the effects of inflation rate on stock market returns differ during and after compared to before the 2008 GFC? To what degree did average stock market returns differ during and after compared to before the occurrence of the 2008 GFC? For a deeper understanding of the relationship between inflation rate and stock market returns, these questions need to be adequately answered.

The rest of the paper is organized as follows. Section 2 provides a brief literature review. Section 3 outlines the adopted research methodology whereas section 4 discusses the data and sources. The empirical results and discussion are presented in section 5 while section 6 concludes.

\section{Literature review}

Theoretical literature on the nature of relationship between inflation rate and stock returns suffers from lack of unanimity, especially among the leading models namely the Fisher Effect (Fisher,1930), Proxy Effect (Fama,1981) and Tax Effect Hypothesis (Feldstein, 1980).

Fisher (1930) argued that expected rate of return of a financial asset (reflected by the nominal interest rate) should consist of expected real rate of interest and expected rate of inflation. According to this theory, expected real rate of interest is constant while the nominal rate of interest reflects all available information on the future levels of inflation rate. Consequently, the theory asserts that a permanent change in inflation rate should cause an equal change in the nominal interest rate. This suggests that nominal interest rate should respond positively on a one-for-one basis to a change in expected inflation rate. Generalized to real assets, the theory suggests that common stock returns should consist of real stock returns and expected inflation rate. With the real stock returns being constant, an increase in expected inflation rate should lead to a one-for-one increase in common stock returns. This strict interpretation of the Fisher Effect suggests that stocks should provide 
an efficient hedge against rising inflation rates. Hence, if the theory holds, returns from stocks should compensate investors for increases in expected as well as in unexpected inflation rate.

On the contrary, the Proxy Effect (Fama, 1981) asserts that a negative correlation, which is not causal, exists between stock market returns and inflation rate. The theory argues that this negative correlation is derived from the positive correlation between stock market returns and real economic activity coupled with the negative correlation between inflation rate and real economic activity. According to the theory, rising inflation rate is expected to depress real economic activity. This should in turn negatively affect future corporate cash flows and reduce stock market returns.

Conversely, Feldstein (1980) argued that during inflationary periods, firms are subjected to increased tax liabilities which tend to reduce their real earnings. As result, rational investors develop a tendency to reduce common stock valuations during such periods to account for the effect of inflation. The argument then is that this reduction in valuation causes a decline in stock market returns. In other words, the Tax Effects Hypothesis (TEH) asserts that rising inflation rate increases the tax burden of firms which in turn reduces their real profits and depresses stock market returns. The theory therefore argues that rising inflation rate is negatively correlated with stock market returns.

Based on these varied theoretical arguments, it appears that the theoretical literature on the relationship between inflation rate and stock market returns remains mixed and inconclusive. Furthermore, none of these theories explains how the relationship between inflation rate and stock market returns is moderated by external events such as shocks from the 2008 GFC.

Likewise, majority of empirical literature pays very little attention to the likely effects of events such as the 2008 GFC on the relationship between inflation rate and stock market returns. They instead focus on the main effects (additive) regression techniques which yield mixed and inconclusive results (Ahmad, Rehman \& Raoof, 2010; Buyuksalvarci, 2010; Kirui, Wawire \& Onono, 2014; Kumar \& Puja, 2012; Ouma \& Miriu, 2014). However, shocks from events such as financial crises should moderate the relationship between stock market returns and inflation rate (Amaefula \& Asare, 2013; Chan, Gup \& Pan, 1997; Kganyago \& Gumbo, 2015). For instance, evolution of stock market returns and inflation rate might respond differently before, during and after an occurrence of a financial crisis depending on how investors perceive the crisis (Copeland et al., 2005).

Besides, shocks from the 2008 GFC are expected to have different effects on emerging and developed markets owing to differences in their respective macroeconomic policies, trade policies and domestic financial 
systems (Berkmen et al., 2012). For example, Ali and Afzal (2012) found that the 2008 GFC significantly depressed stock market returns in India whereas Chong (2011) concluded that the 2008 GFC had mild effects on stock market returns in the US. Additionally, the 2008 GFC had significant effects on the energy sector (Guo, Chen \& Huang, 2011) which might have significantly influenced the behaviour of commodity prices. Furthermore, a financial crisis could lead to an economic slowdown and depressed capital markets which might in turn trigger sharp declines in commodity prices and inflation rate (Bermingham et al., 2012).

On the whole, existing theoretical and empirical literature does not seem to provide adequate attention to how shocks from events such as the 2008 GFC might affect the relationship between inflation rate and stock market returns.

\section{Methodology}

\section{Empirical Models}

The study adopted the Fisher Effect model (Fisher, 1930) and represented the relationship between inflation rate and the NSE 20 Share Index returns as follows:

$$
N R_{t} / F_{t-1}=n r_{t} / F_{t-1}+E\left(\Pi_{t} / F_{t-1}\right) \text {. }
$$

Where $N R_{t}$ is the nominal NSE 20 Index return from t-1 to t, $n r_{t}$ is the real NSE 20 Index return from $\mathrm{t}-1$ to $\mathrm{t}$, and $\Pi_{t}$ is the rate of inflation from $t-1$ to $t . F_{t-1}$ is the set of information available at time $t-1$, and $E$ is the expectation operator.

Furthermore, based on rational expectations, this study assumed that movements in actual and expected values of inflation rate coincide (Rushdi et al., 2012). The study therefore represented equation 3.1 as:

$$
N R_{t}=\alpha_{0}+\alpha_{1} n r_{t}+\alpha_{2} \Pi_{t}
$$

Since the stock market is expected to act as a complete hedge against inflation, $\alpha_{2}=1$ (in the strictest interpretation of Fisher Effect).

\section{The Main Effects Regression Model}

To determine whether there was a difference in the extent to which the stock market priced different types of inflation rate, this study considered two measures of inflation rate namely; the month-on-month inflation rate (which represents a short term rate) and the year-on-year inflation rate (which is a long term rate). This consideration was informed by the fact that stock market prices often represent valuations of cash flows projected over a long period into the future (Alagidede \& Panagiotidis, 2010). As a result, monthly stock market returns are more likely to have a stronger relationship not with changes in current inflation rate (e.g. month-on-month inflation 
rate) but with changes in inflation rate projected into the future (e.g. year-onyear inflation rate). Consequently, to examine the long run relationship between each of the measures of inflation rate and stock market returns, this study first conducted stationarity tests on the individual variables and their cointegrating residuals to determine their orders of integration. Evidence of stationarity of the cointegrating residuals implied that the study could run the following additive regression models:

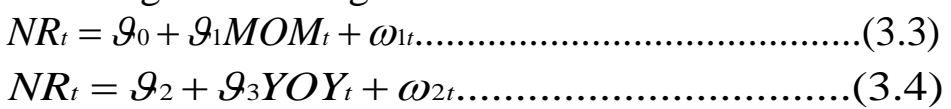

where $M O M_{t}$ is the month-on-month inflation rate, $Y O Y_{t}$ is the yearon-year inflation rate while $\vartheta_{1}$ and $\vartheta_{2}$ measure the long run effect of the month-on-month inflation rate and year-on-year inflation rate on stock market returns, respectively. This study expected $\vartheta_{1}$ and $\vartheta_{3}$ to be positive according to FE (Fisher, 1930).

However, the FE does not consider how shocks from events such as the 2008 GFC could have moderated the relationship between inflation rate and stock market returns. This study therefore extended the FE by adopting a product-term regression model to capture the effects of the 2008 GFC.

\section{Product Term Regression Models}

The study tested the direct effect of the 2008 GFC on stock market returns as well as the moderating effect of shocks from the 2008 GFC on the relationship between inflation rate and stock market returns. It split the sample period into (a) the period before the 2008 GFC crisis (from $1^{\text {st }}$ January 1993 to $31^{\text {st }}$ December, 2007); (b) the period during the 2008 GFC crisis (from $1^{\text {st }}$ January 2008 to $30^{\text {th }}$ June 2009); and (c) the period after the 2008 GFC crisis (from $1^{\text {st }}$ July 2009 to $31^{\text {st }}$ December 2015). Three dummy variables were used to capture the three different periods with $D_{\text {beforeGFC }}$ representing the period before the crisis; $D_{\text {duringGFC }}$ for the period during the crisis; and $D_{\text {afterGFC }}$ for the period after the crisis. $D_{\text {beforeGFC }}$ was coded 1 for the period before the crisis, 0 for other periods; $D_{\text {duringGFC }}$ was 1 for the period during the crisis, 0 for other periods; and $D_{\text {afterGFC }}$ was is 1 for the period after the crisis, and 0 otherwise.

This study then estimated the direct effect of the 2008 GFC on stock market returns as well as the moderating effect of the 2008 GFC on the relationship between inflation rate and stock market returns during and after the crisis period in comparison to the period before the crisis. This was done by estimating the following models extended from equations 3.3 and 3.4 by incorporating the dummy variables for the 2008 GFC: 


$$
\begin{aligned}
& N R_{t}=\phi_{0}+\phi_{1} D_{\text {duringGFC }}+\phi_{2} \mathrm{D}_{\text {afterGFC }}+\phi_{3} \mathrm{MOM}_{\mathrm{t}}+\phi_{4} \mathrm{MOM}_{\mathrm{t}} \mathrm{D}_{\text {duringGFC }}+\phi_{5} \mathrm{MOM}_{t} D_{\text {afterGFC }}+\gamma_{11 \ldots . . .} \\
& N R_{t}=\phi_{6}+\phi_{7} \mathrm{D}_{\text {duringGFC }}+\phi_{8} \mathrm{D}_{\text {afterGFC }}+\phi_{9} \mathrm{YOY}_{\mathrm{t}}+\phi_{10} \mathrm{YOY}_{\mathrm{t}} \mathrm{D}_{\text {duringGFC }}+\phi_{11} \mathrm{YOY}_{\mathrm{t}} \mathrm{D}_{\text {afterGFC }}+\gamma_{2 t \ldots \ldots . . .}
\end{aligned}
$$

where $\phi_{0}$ in equation 3.5 is the average stock market return before the crisis, $\phi_{1}$ measures the average stock market return during the crisis period compared to average stock market return before the crisis. If positive, $\phi_{1}$ indicates that stock market returns were, on average, higher during the crisis compared to before the crisis. $\phi_{3}$ reflects the effect of a unit increase in the month-on-month inflation rate on stock market returns before the crisis began. A positive $\phi_{3}$ shows that a unit increase in the month-on-month inflation rate led to an increase in stock market returns before the crisis began. On the other hand, $\phi_{4}$ measures the effect of a unit increase in the month-on-month inflation rate on stock market returns for the period during the crisis minus the corresponding effect for the period before the crisis. A positive $\phi_{4}$ therefore suggests that a unit increase in the month-on-month inflation rate had a higher positive effect on stock market returns during the crisis compared to a corresponding effect before the crisis. Similar interpretations held for the coefficients in equation 3.6.

To examine how stock market returns differed over the three periods (i.e. before, during and after the 2008 GFC) as a function of the mean values of month-on-month inflation rate and year-on-year inflation rate, this study replaced the values of the two measures of inflation rate in equations 3.5 and 3.6 by their respective mean centered values. The mean centered values were obtained by subtracting the mean of each of the independent variables from the original values. Consequently, the following models were estimated:

$$
\begin{aligned}
& N R t=\phi_{12}+\phi_{13} \mathrm{D}_{\text {duringGFC }}+\phi_{14} \mathrm{D}_{\text {afterGFC }}+\phi_{15} \mathrm{MOM}_{\mathrm{ct}}+\phi_{16} \mathrm{MOM}_{\mathrm{c}} \mathrm{D}_{\text {duringGFC }}+\phi_{17} \mathrm{MOM}_{\mathrm{c}} D_{\text {afterGFC }}+\gamma_{3 t \ldots . .} \\
& N R_{t}=\phi_{18}+\phi_{19} \mathrm{D}_{\text {duringGFC }}+\phi_{20} \mathrm{D}_{\text {afterGFC }}+\phi_{21} \mathrm{YOY}_{\mathrm{ct}}+\phi_{22} \mathrm{YOY}_{\mathrm{ct}} \mathrm{D}_{\text {duringGFC }}+\phi_{23} \mathrm{YOY}_{\mathrm{ct}} D_{\text {afterGFC }}+\gamma_{4 \mathrm{t}} \ldots .
\end{aligned}
$$

Where $\phi_{12}$ in equation 3.7 is the average stock market return for the period before the crisis at the mean month-on-month inflation rate, $\phi_{13}$ is the average stock market return for the period during the crisis minus the average stock market return for the period before the crisis at the mean month-on-month inflation rate. If positive, $\phi_{13}$ suggests that stock market returns were higher during the crisis compared to before the crisis at the mean month-on-month inflation rate. $\phi_{15}$ measures the effect of a unit increase in the month-on-month inflation rate on stock market returns before 
the crisis period when the month-on-month inflation rate was at its mean value. Therefore a positive $\phi_{15}$ implies that when the month-on-month inflation rate was at its mean value, a unit increase in its value had a positive effect on stock market returns before the crisis began. $\phi_{16}$ measures the extent to which the mean difference in average stock market returns between the crisis period and the period before the crisis changed in response to a unit increase in the month-on-month inflation rate when the month-on-month inflation rate was held at its mean value. If positive, $\phi_{16}$ indicates that for a unit increase in the month-on-month inflation rate, stock market returns during the crisis increased by a bigger margin compared to stock market returns before the crisis when the month-on-month inflation rate was average. Similar interpretations were applied to the coefficients of equation 3.8.

The study hypothesized that:

$$
\begin{aligned}
& \phi_{0}>0, \phi_{1}<0, \phi_{2}<0, \phi_{3}>0, \phi_{4}<0, \phi_{5}<0, \phi_{6}>0, \phi_{7}<0, \phi_{8}<0, \phi_{9}>0, \\
& \phi_{10}<0, \phi_{11}<0, \phi_{12}>0, \phi_{13}<0, \phi_{14}<0, \phi_{15}>0, \phi_{16}<0, \phi_{17}<0, \phi_{18}>0, \\
& \phi_{19}<0, \phi_{20}<0, \phi_{21}>0, \phi_{22}<0, \text { and } \phi_{23}<0
\end{aligned}
$$

This study also created scenarios for average stock market returns during and after the crisis relative to before the crisis at "low", "medium" and "high" levels of each of the two measures of inflation rate. The "low" value of month-on-month inflation rate was constructed by subtracting the standard deviation of the month-on-month inflation rate from the mean of the month-on-month inflation rate and then deducting this (difference) from the original values of the month-on-month inflation rate. The "high" value was derived by adding the standard deviation of the month-on-month inflation rate to its mean value and subtracting this (sum) from the original values of the month-on-month inflation rate. "Medium" values of the month-on-month inflation rate were represented by the mean centered values of the month-onmonth inflation rate. The same procedure was followed to obtain low, medium and high values of the year-on-year inflation rate.

Consequently, average stock market returns during and after the crisis compared to before the crisis when the month-on-month inflation rate was "average/medium" was obtained directly from equation 3.7 because the month-on-month inflation rate was mean centered. On the other hand, average stock market returns during and after the crisis compared to before the crisis at low values of the month-on-month inflation rate and year-onyear inflation rate were obtained from the following models:

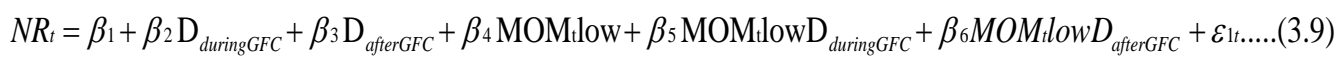


$N R_{\mathrm{t}}=\beta_{7}+\beta_{8} \mathrm{D}_{\text {duringGFC }}+\beta_{9} \mathrm{D}_{\text {afterGFC }}+\beta_{10}$ YOY tow $+\beta_{11}$ YOYtlowD $_{\text {duringGFC }}+\beta_{12} Y_{\text {YOY low }} D_{\text {afferGFC }}+\varepsilon_{2 t} \ldots . .$.

Where MOMtlow represents low month-on-month inflation rate and YOY tow is the low year-on-year inflation rate.

The study expected the following conditions to hold: $\beta_{2}<0, \beta_{3}<0, \beta_{4}>0, \beta_{5}<0, \beta_{6}<0, \beta_{8}<0, \beta_{9}<0, \beta_{10}>0, \beta_{11}<0$, and $\beta_{12}<0$.

Likewise, average stock market returns during and after the crisis compared to before the crisis at high values of the month-on-month inflation rate and year-on-year inflation rate were obtained using the following models:

$$
\begin{aligned}
& N R_{t}=\beta_{13}+\beta_{14} \mathrm{D}_{\text {duringGFC }}+\beta_{15} \mathrm{D}_{\text {afferGFC }}+\beta_{16} \mathrm{MOM} \mathrm{High}+\beta_{17} \mathrm{MOM}_{\mathrm{t}} \mathrm{HighD}_{\text {duringGFC }}+\beta_{18} M O M_{t} \text { ligh } D_{\text {afferGFC }}+\varepsilon 4 t \ldots . \\
& N R_{t}=\beta_{19}+\beta_{20} \mathrm{D}_{\text {duringGFC }}+\beta_{21} \mathrm{D}_{\text {afferGFC }}+\beta_{22} \mathrm{YOY}_{\mathrm{t} H i g h}+\beta_{23} \mathrm{YOY}_{\mathrm{t}} \mathrm{HighD}_{\text {duringGFC }}+\beta_{24} \mathrm{YOY}_{\mathrm{t}} \text { ligh } D_{\text {afferGFC }}+\varepsilon_{5}
\end{aligned}
$$

Where $\mathrm{MOM}_{\mathrm{t}}$ High stands for high month-on-month inflation rate.

This study expected the following conditions to hold: $\beta_{14}<0, \beta_{15}<0, \beta_{16}<0, \beta_{17}<0, \beta_{18}<0, \beta_{20}<0, \beta_{21}<0, \beta_{22}<0, \beta_{23}<0$, and $\beta_{24}<0$.

\section{Data and sources}

This study used monthly published time series data with the full sample period from $1^{\text {st }}$ January 1993 to $31^{\text {st }}$ December 2015 which yielded a total of 276 observations. The variables comprised monthly NSE 20 Share index drawn from the Nairobi Securities Exchange (NSE), month-on-month inflation rate and year-on-year inflation rate obtained from the Kenya Bureau of Statistics (KEBS) as well as a dummy variable representing presence or absence of shocks from the 2008 GFC.

Table 4.1: Description and Measurement of Stock Returns and Inflation Rate

\begin{tabular}{|c|c|c|}
\hline $\begin{array}{c}\text { Variable name } \\
\begin{array}{c}\text { Share Index } \\
\text { nominal returns }\end{array}\end{array}$ & Notation & $\begin{array}{c}\text { Measurement } \\
\text { as percentage change in closing NSE 20 Share Index } \\
\text { between successive months as: } \\
N R_{t}=\ln \left(\frac{N S E_{t}}{N S E_{t-1}}\right) x 100 \text {, where } N S E_{t} \text { is the closing } \\
\text { NSE 20 Share index at time t. }\end{array}$ \\
\hline $\begin{array}{c}\text { Month inflation } \\
\text { rate }\end{array}$ & $M O M_{t}$ & $\begin{array}{c}\text { Monthly percentage change in Consumer Price Index series } \\
\text { computed as: } M O M_{t}=\ln \left(\frac{C P I_{t}}{C P I_{t}-1}\right) x 100 \text { where } C P I_{t} \\
\text { is the value of consumer price index at month t. MOMt } \\
\text { captures the short run inflation dynamics, has less variance } \\
\text { and high forecast ability which could be helpful in portfolio } \\
\text { adjustment. }\end{array}$ \\
\hline
\end{tabular}




\begin{tabular}{|c|c|c|}
\hline $\begin{array}{c}\text { Year-on-Year } \\
\text { inflation rate }\end{array}$ & $Y O Y_{t}$ & $\begin{array}{c}\text { Is the yearly percentage change in the CPI series computed } \\
\text { as: } \\
Y O Y_{\text {Jan 2010 }}=\left(\frac{C P I_{\text {Jan } 2010}}{C P I_{\text {Jan } 2009}}-1\right) x 100 \text {. YOYt captures long } \\
\text { run dynamics of inflation and has high variance and low } \\
\text { forecast ability. Might hence be helpful in tracking the } \\
\text { inflation trend by the central bank. }\end{array}$ \\
\hline $\begin{array}{c}\text { Dummy variable } \\
\text { for the 2008 } \\
\begin{array}{c}\text { Global Financial } \\
\text { Crisis }\end{array}\end{array}$ & $D_{G F C}$ & $\begin{array}{c}\text { It takes the value } 1 \text { for the period before the crisis, 0 } \\
\text { otherwise; } 1 \text { for the period during the crisis, 0 otherwise; and } \\
\text { 1 for the period after the crisis, 0 otherwise. The three } \\
\text { periods were chosen following the FRBSF (2010), NBER } \\
\text { (2008), Usman (2010), Adamu (2010) and Ali and Afzal } \\
\text { (2012). }\end{array}$ \\
\hline
\end{tabular}

Notes: FRBSF is Federal Reserve Bank of San Francisco, and NBER is the National Bureau of Economic Research.

\section{Results and discussion Descriptive Statistics}

The study presents the summary statistics of stock market returns, month-on-month inflation rate and year-on-year inflation rate in Table 5.1. The analysis was conducted for the whole sample period as well as for the periods before, during and after the crisis. This allowed the study to examine differences in the effects of the 2008 GFC on the individual variables. Descriptive statistics for the sub-periods are provided in Table A1 at the Appendix.

Table 5.1: Summary of Descriptive Statistics for Whole Sample

\begin{tabular}{|c|c|c|c|}
\hline & $N R_{t}$ & $M O M_{t}$ & $Y O Y_{t}$ \\
\hline Mean & 0.45 & 0.77 & 10.54 \\
\hline Median & 0.19 & 0.56 & 7.53 \\
\hline Maximum & 41.81 & 7.71 & 61.54 \\
\hline Minimum & -25.67 & -2.45 & -3.66 \\
\hline Std. Dev. & 6.83 & 1.37 & 10.81 \\
\hline Skewness & 0.96 & 1.59 & 2.74 \\
\hline Kurtosis & 9.65 & 8.62 & 11.03 \\
\hline Jarque-Bera & 551.51 & 479.67 & 1087.01 \\
\hline Probability & 0.00000 & 0.00000 & 0.00000 \\
\hline Sum Sq. Dev. & 12819.48 & 515.73 & 32123.47 \\
\hline Observations & 276 & 276 & 276 \\
\hline
\end{tabular}

Notes: $N R_{t}$ is log difference of the NSE 20 Share Index, $M O M_{t}$ is the month-on-month inflation rate, and $Y_{Y} O Y_{t}$ is the year-on-year inflation rate.

Table 5.1 reveals that the mean values of all the variables are positive with the mean of the year-on-year inflation rate being much higher than that of the month-on-month inflation rate while that of stock market returns is the lowest. This suggests that higher values of both measures of inflation rate could have depressed the performance of the stock market. Furthermore, all 
the variables recorded excess positive kurtosis, suggesting that they individually posed lesser risk of extreme outcomes. Additionally, all the variables had positive skewness which implies that their actual values were likely to deviate further upwards from their mean values.

Furthermore, the wide range in the year-on-year inflation rate (see maximum of 61.54 versus minimum of -3.66) suggests that the variable rose significantly during the period. On the other hand, the large negative value of the NSE 20 Share Index returns (see the large minimum of -25.67) suggests that demand for the stock market returns might have decreased significantly over the period. However, the month-on-month inflation rate appears to have been the least volatile which seems to support the preference often given to the variable by portfolio managers in the rebalancing of portfolios.

On splitting the sample into the pre, during and post crisis periods, Table A1 at the Appendix reveals relatively higher mean stock market returns for the pre-crisis period compared to the mean stock market returns for the whole sample period. This suggests that the 2008 GFC had significant direct depressing effects on stock market returns since by partialling out the period during and after the 2008 GFC, a significant increase in the stock market returns seems to have occurred. Additional evidence for this view is provided by the fact that stock market returns were virtually negative during the crisis period (see Table A1 at the Appendix).

In contrast, the mean values of both measures of inflation rate were low before the crisis began but increased during the crisis before declining slightly after the crisis (see Table A1). This suggests that shocks from the 2008 GFC could have depressed economic activities during the crisis period leading to scarcity of goods. Consequently, the supply constraint might have triggered an increase in general prices during the crisis period. However, economic recovery and subsequent gradual increase in the supply of goods and services might have eased off pressure on the general prices after the crisis.

\section{Results of ADF, PP and KPSS Unit Root Tests}

This study determined whether the individual macroeconomic variables and stock market returns were stationary or nonstationary in their level forms. To do this, it conducted ADF, PP and ADF unit root tests. Table 5.2 presents the results of the ADF, PP and KPSS tests when the intercept and trend were included.

Table 5.2: Results for Unit Root Tests using ADF, PP and KPSS Tests (Intercept and Trend)

\begin{tabular}{|c|c|c|c|c|c|c|}
\hline \multirow{2}{*}{$\begin{array}{c}\text { Variable } \\
\text { symbols }\end{array}$} & \multicolumn{2}{|c|}{ ADF Test } & \multicolumn{2}{|c|}{ PP Test } & \multicolumn{2}{c|}{ KPSS Test } \\
\cline { 2 - 7 } & Level & $\begin{array}{c}1^{\text {st }} \\
\text { Difference }\end{array}$ & Level & $\begin{array}{c}1^{\text {st }} \\
\text { Difference }\end{array}$ & Level & $\begin{array}{c}1^{\text {st }} \\
\text { Difference }\end{array}$ \\
\hline$N R_{t}$ & $-4.869^{* * *}$ & $-7.509^{* * *}$ & $\begin{array}{c}- \\
13.089 * * *\end{array}$ & $-145.96^{* * *}$ & 0.102 \\
\hline
\end{tabular}




\begin{tabular}{|c|c|c|c|c|c|c|}
\hline MOM & $-7.089^{* * *}$ & $-8.890^{* * *}$ & $\begin{array}{c}- \\
10.669^{* * *}\end{array}$ & $-65.543^{* * *}$ & 0.127 & 0.348 \\
\hline YOY & $-7.514^{* * *}$ & $-5.426^{* * *}$ & -3.045 & $-13.621^{* * *}$ & 0.159 & 0.029 \\
\hline
\end{tabular}

Notes: $* * * 1 \%$ significance, $* * 5 \%$ significance, $* 10 \%$ significance (i.e., $* * * \mathrm{p}<0.01,{ }^{* *} \mathrm{p}$

$\left.<0.05,{ }^{*} \mathrm{p}<0.1\right)$. Null hypothesis under the ADF and PP tests is that the variable is I (1).

Null hypothesis under the KPSS test is that the variable is stationary. LM critical values are

( 0.216 at $1 \%, 0.146$ at $5 \%$, and 0.119 at $10 \%)$. Fail to reject the null hypothesis if computed

LM statistic is lower than critical values, reject if higher. $N R_{t}$ is log difference of the NSE

20 Share Index, $M O M_{t}$ is month-on-month inflation rate, and $Y_{0} Y_{t}$ is the year-on-year inflation rate.

The ADF test results suggest that all the individual variables are stationary in level form. On the other hand, the PP test fails to reject the null hypothesis of nonstationarity for the year-on-year inflation rate. The results of KPSS test demonstrate that the computed LM statistic for the year-on-year inflation rate was higher than the critical value at 5 percent significance level. The computed LM statistic for the NSE 20 Share Index returns and month-on-month inflation rate were however lower than the critical values at 5 percent significance level suggesting that the two variables were stationary in level form.

However, ADF, PP and KPSS test results (see Table A2 at the Appendix) revealed that all the cointegrating residuals were stationary. This suggests that each of the measures of inflation rate was cointegrated with stock market returns. This made it possible to estimate the long run relationship between the two measures of inflation rate and stock market returns using levels of the variables.

\section{Results of Additive Regressions versus Product-Term Models}

This study compared the results of the main effects (additive) models to those of product-term models using observed values and mean centred values of the month-on-month inflation rate and year-on-year inflation rate. Table 5.3 presents results from equations 3.3 to 3.8 .

Table 5.3: Estimates of Additive Regressions versus Product-Term Models

\begin{tabular}{|c|c|c|c|c|c|c|}
\hline \multicolumn{7}{|c|}{ Dependent variable: Stock market returns } \\
\hline $\begin{array}{c}\text { Independent } \\
\text { variables }\end{array}$ & \multicolumn{3}{c|}{ Additive regressions } & \multicolumn{4}{c|}{ Equation (3.5) } \\
\hline \multicolumn{3}{|c|}{ Equation ( 3.3 ) } & \multicolumn{3}{c|}{. } & \multicolumn{3}{c|}{ t-ratio } & Coefficient & S.E. & t-ratio \\
\hline & Coefficient & S.E. & term regressions \\
\hline Intercept & -0.011 & 0.469 & -0.022 & 0.149 & 0.536 & 0.279 \\
\hline$M O M t$ & 0.595 & 0.299 & $1.989 * *$ & 0.869 & 0.468 & $1.860^{*}$ \\
\hline$D_{\text {duringGFC }}$ & & & & 0.019 & 4.428 & 0.004 \\
\hline$D_{\text {afterGFC }}$ & & & & 1.014 & 0.919 & 1.103 \\
\hline$M O M_{t} D_{\text {duringGFC }}$ & & & & -3.591 & 3.494 & -1.028 \\
\hline
\end{tabular}




\begin{tabular}{|c|c|c|c|c|c|c|}
\hline$M O M t D_{a f t e r G F C}$ & & & & -2.339 & 0.822 & $-2.844 * * *$ \\
\hline & & & & \multicolumn{3}{|c|}{ Equation (3.6) } \\
\hline & Coefficient & S.E. & t-ratio & Coefficient & S.E. & t-ratio \\
\hline Intercept & & & & 0.823 & 0.602 & 1.367 \\
\hline MOMct & & & & 0.869 & 0.468 & $1.860 *$ \\
\hline$D_{\text {duringGFC }}$ & & & & -2.759 & 2.685 & -1.028 \\
\hline$D_{\text {afterGFC }}$ & & & & -0.796 & 0.802 & -0.993 \\
\hline$M O M_{c t} D_{\text {duringGFC }}$ & & & & -3.591 & 3.494 & -1.028 \\
\hline$M O M_{c t} D_{a f t e r G F C}$ & & & & -2.339 & 0.822 & $-2.844 * * *$ \\
\hline \multicolumn{4}{|c|}{ Equation (3.4) } & \multicolumn{3}{|c|}{ Equation (3.7) } \\
\hline & Coefficient & S.E. & t-ratio & Coefficient & S.E. & t-ratio \\
\hline Intercept & -1.256 & 0.556 & $-2.259 * *$ & -1.305 & 0.800 & -1.630 \\
\hline$Y O Y_{t}$ & 0.162 & 0.037 & $4.389 * * *$ & 0.191 & 0.0715 & $2.669 * * *$ \\
\hline$D_{\text {duringGFC }}$ & & & & 4.945 & 12.239 & 0.404 \\
\hline$D_{\text {afterGFC }}$ & & & & 3.111 & 1.3711 & $2.269 * *$ \\
\hline$Y O Y D_{\text {duringGFC }}$ & & & & -0.644 & 0.840 & -0.766 \\
\hline \multirow[t]{3}{*}{$Y O Y_{t} D_{a f t e r G F C}$} & & & & -0.386 & 0.143 & $-2.702 * * *$ \\
\hline & & & & \multicolumn{3}{|c|}{ Equation (3.8) } \\
\hline & Coefficient & S.E. & t-ratio & Coefficient & S.E. & t-ratio \\
\hline Intercept & & & & 0.707 & 0.509 & 1.389 \\
\hline$Y O Y_{c t}$ & & & & 0.191 & 0.072 & $2.669 * * *$ \\
\hline$D_{\text {duringGFC }}$ & & & & -1.842 & 3.857 & -0.478 \\
\hline$D_{\text {afterGFC }}$ & & & & -0.961 & 0.845 & -1.137 \\
\hline$Y O Y_{c t} D_{\text {duringGFC }}$ & & & & -0.644 & 0.840 & -0.766 \\
\hline$Y O Y_{c t} D_{a f t e r G F C}$ & & & & -0.3864 & 0.143 & $-2.702 * * *$ \\
\hline
\end{tabular}

Notes: The asterisk * indicate the significance at $10 \%$ level, $* *$ at $5 \%$ level and $* * *$ at $1 \%$ level. NRt is log difference of the NSE 20 Share Index, MOMt is the month-on-month inflation rate, and YOYt is the year-on-year inflation rate. MOMct and YOYct are mean centered values of the respective variables.

The results from equations 3.3 and 3.4 (the additive models) indicate that the average stock market returns were negative while a unit increase in the month-on-month inflation rate and year-on-year inflation rate had significant positive main effects on stock market returns. On the other hand, equations 3.5 and 3.6 (the product-term models) reveal that while a unit increase in month-on-month inflation rate and year-on-year inflation rate had significant positive effects on stock market returns before the crisis, a similar increase in both variables had significant depressing effects on stock market returns after the crisis compared to before the crisis. These detailed analyses 
cannot be gleaned from the additive models. Additionally, the product-term models indicate that these depressing effects were the same at both observed and mean centered values of the two measures of inflation rate. This suggests that the 2008 GFC had a significant moderating effect on the relationship between inflation rate and stock market returns. It further shows that the Kenyan stock market is highly sensitive to increases in inflation rate especially when recovering from a financial turmoil. The product-term models also reveal that a unit increase in either measure of inflation rate had a depressing effect on stock market returns during the crisis compared to before the crisis at observed and medium values.

Likewise, the product-term equations show that average stock market returns were significantly higher after the crisis compared to before the crisis at observed values of both measures of inflation rate. However, the same were lower after the crisis compared to before the crisis at medium values of the two measures of inflation rate. This suggests that the 2008 GFC had more direct depressing effects on stock market returns when both measures of inflation were at their medium values than at observed values. Additionally, average stock market returns were higher during and after the crisis compared to before the crisis at observed values of the two measures of inflation rate. In contrast, average stock market returns were lower during and after the crisis compared to before the crisis at medium values of the two measures of inflation rate. These results indicate that the 2008 GFC had more direct depressing effects on the stock market when the economy was experiencing medium levels of inflation rate.

These results are in agreement with those found by Ali and Afzal (2012) who established that the 2008 GFC resulted into a significant decline in stock market returns in India. The results also support Amaefula and Asare (2013) who established that the global financial crisis had significant effect on the correlation between stock market returns and exchange rate in Nigeria.

\section{Results of Stock Returns as a Function of Low and High Values of Inflation Rate}

The study also investigated the effect of the 2008 GFC on the relation between inflation rate and stock market returns at low and high values of the month-on-month inflation rate and year-on-year inflation rate. Table 5.4 presents the scenarios of average stock market returns as a function of the low and high values of the two measures of inflation rate derived from equations 3.9 and 3.12 . 
Table 5.4: Scenarios of Stock Market Returns as a Function of Low and High values of Inflation Rate

\begin{tabular}{|c|c|c|c|}
\hline \multicolumn{4}{|c|}{ Dependent Variable: $N R_{t}$} \\
\hline Regressors & Coefficient & S.E. & t-ratio \\
\hline Intercept & -0.369 & 0.638 & -0.577 \\
\hline MOMtlow & 0.869 & 0.468 & $1.860^{*}$ \\
\hline$D_{\text {duringGFC }}$ & 2.158 & 6.254 & 0.345 \\
\hline$D_{\text {afterGFC }}$ & 2.407 & 1.246 & $1.932 *$ \\
\hline$M O M$ tlow $D_{\text {duringGFC }}$ & -3.591 & 3.494 & -1.028 \\
\hline \multirow[t]{2}{*}{$M O M$ tlowD $_{\text {afterGFC }}$} & -2.339 & 0.822 & $-2.844 * * *$ \\
\hline & Coefficient & S.E. & t-ratio \\
\hline Intercept & 2.014 & 1.066 & $1.888^{*}$ \\
\hline MOMthigh & 0.869 & 0.468 & $1.860^{*}$ \\
\hline$D_{\text {duringGFC }}$ & -7.678 & 4.595 & $-1.671^{*}$ \\
\hline$D_{\text {afterGFC }}$ & -3.999 & 1.506 & $-2.654 * * *$ \\
\hline MOMthigh $D_{\text {duringGFC }}$ & -3.591 & 3.494 & -1.028 \\
\hline \multirow[t]{2}{*}{ MOMthighD $D_{\text {afterGFC }}$} & -2.339 & 0.822 & $-2.844 * * *$ \\
\hline & Coefficient & S.E. & t-ratio \\
\hline Intercept & -1.356 & 0.816 & $-1.663 *$ \\
\hline YOYtlow & 0.191 & 0.072 & $2.669 * *$ \\
\hline$D_{\text {duringGFC }}$ & 5.119 & 12.463 & 0.411 \\
\hline$D_{\text {afterGFC }}$ & 3.215 & 1.403 & $2.291^{* *}$ \\
\hline YOYtlow $D_{\text {duringGFC }}$ & -0.644 & 0.840 & -0.766 \\
\hline \multirow[t]{2}{*}{ YOYtlowD $D_{\text {afterGFC }}$} & -0.3864 & 0.1430 & $-2.702 * * *$ \\
\hline & Coefficient & S.E. & t-ratio \\
\hline Intercept & 2.770 & 1.024 & $2.706 * * *$ \\
\hline YOYthigh & 0.191 & 0.072 & $2.669 * * *$ \\
\hline$D_{\text {duringGFC }}$ & -8.803 & 6.278 & -1.402 \\
\hline$D_{\text {afterGFC }}$ & -5.138 & 2.059 & $-2.495^{* *}$ \\
\hline$Y O Y$ thigh $D_{\text {duringGFC }}$ & -0.644 & 0.840 & -0.766 \\
\hline YOYthighD ${ }_{\text {afterGFC }}$ & -0.386 & 0.1430 & $-2.702 * * *$ \\
\hline
\end{tabular}

Notes: NRt is the log difference of the NSE 20 Share Index, MOMt is the month-on-month inflation rate, YOYt is the year-on-year inflation rate.

Table 5.4 reveals that a unit increase in month-on-month inflation rate had the same significant positive effect on stock market returns before the crisis at both low and high values of the variable. The same applied to 
stock market returns at low and high values of the year-on-year inflation rate. However, a unit increase in the month-on-month inflation rate led to a significant decline in stock market returns after the crisis compared to before the crisis at both low and high values of the variable. Likewise, a unit increase in the year-on-year inflation rate led to a significant decline in stock market returns after compared to before the crisis at both low and high values of the variable. These results suggest that the Kenyan stock market remains highly sensitive to any increases in inflation rate after a crisis regardless of the prevailing inflation rate.

The models also show that stock market returns generally declined during compared to before the crisis for a unit increase in either measure of inflation rate, regardless of the level of inflation rate. This suggests that any increases in inflation rate depress the performance of the stock market performance during a financial crisis.

On the other hand, Table 5.4 demonstrates that average stock market returns were significantly higher after the crisis compared to before the crisis at low month-on-month inflation rate. However, average stock market returns declined significantly after the crisis compared to before the crisis at high values of the month-on-month inflation rate. Likewise, average stock market returns were significantly higher after the crisis compared to before the crisis at low values of the year-on-year inflation rate but declined significantly after the crisis compared to before the crisis at high values. This suggests that lower values of inflation rate boost the performance of the Kenyan stock market when it is emerging from a crisis. In other words, a stable macroeconomic environment is vital for a stock market recovering from a financial turmoil.

\section{Conclusion}

This study examined the direct effects of the 2008 GFC on stock market returns. It also determined the moderating effect of the 2008 GFC on the relationship between inflation rate and stock market returns. The study employed a product- term regression model and two measures of inflation rate namely; the month-on-month inflation rate and year-on-year inflation rate. It also created scenarios for the effect of the 2008 GFC on stock market returns at low, medium and high values of each of the two measures of inflation rate.

The results revealed that a unit increase in either measure of inflation rate had significant depressing effects on stock market returns after compared to before the 2008 GFC irrespective of whether each of the measures of inflation rate was low, medium or high. This suggests that policymakers as well as stock market regulators need to be extra cautious 
when intervening in the activities of the Kenyan stock market, especially after turbulences such as the 2008 GFC.

The study also established that average stock market returns were significantly higher after the crisis compared to before the crisis at low values of both measures of inflation rate. This implies that the government needs to devise policies that maintain low and stable inflation rate to sustain investor confidence in the stock market, especially after turbulences such as the 2008 GFC.

Additionally, this study indicated that a unit increase in either measure of inflation had significant positive effects on the stock market returns before the 2008 GFC at low, medium or high values of the macroeconomic variable. This implies that investors in the Kenyan stock market are compensated in terms of higher stock returns during periods of rising inflation rate.

The results of this study have provided the first evidence of how product-term regression models can provide deeper insights compared to the widely employed additive or main effects models. This study has also provided exceptional ways of examining the moderating effects of shocks from the 2008 GFC on the relationship between inflation rate and stock market returns.

\section{References:}

1. Adamu, A. (2010). Global Financial Crisis and Nigerian Stock Market Volatility. Proceedings of the National Conference on "Managing the Challenges of Global Financial Crisis in Developing Economies”, 1, 102-113.

2. Ahmad, M.I., Rehman, R. U., and Raoof, A. (2010). Do Interest Rate, Exchange Rate affect Stock Returns? A Pakistani Perspective. International Research Journal of Finance and Economics 50, 146150.

3. Alagidede, P., and Panagotidis, T. (2010). Can Common Stocks Provide a Hedge against Inflation? Evidence from African Countries. Review of Financial Economics 19, 91-100.

4. Ali, R., Afzal, M. (2012), Impact of Global Financial Crisis on stock markets: Evidence from Pakistan and India. Journal of Business Management and Economics 3, 275-282.

5. Amaefula, C.G and Asare, B.K. (2013). Time Varying Correlation of Stock Returns Relative to Exchange Rate and Inflation Rate and also Their Volatilities: Evidence from Nigeria. IOSR Journal of Business and Management (IOSR-JBM) 14, 41-49.

6. Azar, S, A. (2015). The Equity Premium and Inflation: Evidence from the US. Applied Finance and Accounting 1, 30-36. 
7. Buyuksalvarci, A. (2010). The Effects of Macroeconomics Variables on Stock Returns: Evidence from Turkey. European Journal of Social Sciences 14, 404-416.

8. Berkmen, SP, Gelos, G, Rennhack, R and Walsh, JP. (2012).The Global Financial Crisis: Explaining Cross-Country Differences in the Output Impact. Journal of International Money and Finance 31, 4259.

9. Bermingham, C., Coates, D., Larkin, J., O’ Brie D., and O’Reill, G. (2012). Explaining Irish Inflation During the Financial Crisis. Research Technical Paper.

10. Chan, K. C., Gup, B. E., \& Pan, M. S. (1997). International Stock Market Efficiency and Integration: A Study of 18 Nations. Journal of Business Finance and Accounting 24, 803-813.

11. Chen, N. F., Roll, R., \& Ross, S. (1986). Economic Forces and the Stock Market. Journal of Business 59, 383-403.

12. Chong, C. Y. (2011). Effect of Sub-prime Crisis on U.S. Stock Market Return and Volatility. Global Economy and Finance Journal 4, 102-111.

13. Copeland, T., E., Weston, J, F., and Shastri, K. (2005). Financial Theory and Corporate Policy. $4^{\text {th }}$ Ed. Pearson Education.

14. Demirhan, B. (2016). Revisiting the Fisher Hypothesis: Evidence from Turkey based on the Methods of FMOLS, DOLS and CCR. Asian Academic Research Journal of Social Science and Humanities. Vol 3(4).

15. Elton, Edwin J., Martin J. Gruber, Stephen J. Brown and William N. Goetzmann (2011), Modern Portfolio Theory and Investment Analysis, International Student Version, 8ed., John Wiley and Sons, Asia.

16. Fama, E.F. (1981). Stock Returns, Real Activity, Inflation and Money. The American Economic Review 71, 545-556.

17. Federal Reserve Bank of San Francisco (FRBSF) report of 2010.

18. Feldstein, M. (1980). Inflation and Stock Market. American Economic Review 70, 839-849.

19. Fisher, I. (1930). The Theory of Interest Rate, New York: McMillan.

20. Guo, F, Chen, CR and Huang, YS. (2011).Markets Contagion during Financial Crisis: A Regime-switching Approach. International Review of Economics and Finance 20, 95-109.

21. Hamrita, M.E. and Trifi. A. (2011). The Relationship between Interest Rate, Exchange Rate and Stock Price: A Wavelet Analysis. International Journal of Economics and Financial Issues 4, 220-228. 
22. Hautcoeur, P.C. (2011). Why and How to Measure Stock Market Fluctuations? The Early History of Stock Market Indices, with Special Reference to the French Case. Working Paper No. 2006 - 10.

23. Kganyago, T., and Gumbo, V. (2015). An Empirical Study of the Relationship between Money Market Interest Rates and Stock Market Performance: Evidence from Zimbabwe (2009-2013). International Journal of Economics and Financial Issues. 5, 638-646.

24. Kimani, D.K and Mutuku, C.M. (2013). Inflation Dynamics on the Overall Stock Market Performance: The Case of Nairobi Securities Exchange in Kenya. Economics and Finance Review 2, 1-11.

25. Kirui, E., Wawire, H.W.N. and Onono, P.O. (2014). Macroeconomic Variables, Volatility and Stock Market Returns:

A Case Study of Nairobi Securities Exchange, Kenya. International Journal of Economics and Finance 6, 214-228.

26. Kumar, N. P., and Puja, P. (2012). The Impact of Macroeconomic Fundamentals on Stock Prices revisited: An Evidence from Indian Data. MPRA Paper No. 38980.

27. Lo, A.W., Campbell, J.Y., and Mackinlay, A.C. (1997). The Econometrics of Financial Markets, Princeton University, New Jersey (NJ).

28. National Bureau of Economic Research (NBER) report of 2008 on the 2008 Global Financial Crisis.

29. Ouma, W, .O. and Muriu, P. W. (2014). The Impact of Macroeconomic Variables on Stock Market Returns in Kenya. International Journal of Business and Commerce 3, 01-31.

30. Razzaque, H.B., and Olga, P. (2013). Stock Return and Inflation in Kazakhstan, Russia and Ukraine. International Journal of Economics and Finance 5, 253-270.

31. Rushdi, M., Kim, J.H., and Silvapulle, P. (2012). ARDL Bounds Tests and Robust Inference for the Long Run Relationship between Real Stock Returns and Inflation in Austrialia. Economic Modelling 29,535-543.

32. Usman, M. (2010). Global Financial Crisis: It's Impact on Developing Countries and Lessons for Pakistan. IPRI Journal 10, 93118. 


\section{Appendices}

Table A1: Summary Descriptive Statistics for Periods Before, During and After the 2008 GFC

\begin{tabular}{|c|c|c|c|c|c|c|}
\hline $\begin{array}{c}\text { Variable } \\
\text { symbol }\end{array}$ & Period & Mean & S.D & Skewness & Kurtosis & $\begin{array}{c}\text { Jacque-Bera } \\
\text { probability }\end{array}$ \\
\hline NRt & $\begin{array}{c}\text { Pre- } \\
\text { crisis }\end{array}$ & 0.856 & 7.162 & 1.588 & 9.938 & 0.000 \\
\cline { 2 - 7 } & $\begin{array}{c}\text { During } \\
\text { crisis }\end{array}$ & -2.791 & 10.88 & -0.384 & 2.63 & 0.762 \\
\cline { 2 - 7 } & $\begin{array}{c}\text { Post- } \\
\text { crisis }\end{array}$ & 0.262 & 4.269 & -0.39 & 3.436 & 0.273 \\
\hline \multirow{2}{*}{$M_{t}$} & $\begin{array}{c}\text { Pre- } \\
\text { crisis }\end{array}$ & 0.812 & 1.614 & 1.388 & 6.662 & 0.000 \\
\cline { 2 - 7 } & $\begin{array}{c}\text { During } \\
\text { crisis }\end{array}$ & 1.088 & 0.934 & 0.512 & 2.254 & 0.547 \\
\cline { 2 - 7 } & $\begin{array}{c}\text { Post- } \\
\text { crisis }\end{array}$ & 0.614 & 0.631 & 0.935 & 5.594 & 0.000 \\
\hline \multirow{2}{*}{$Y_{t}$} & $\begin{array}{c}\text { Pre- } \\
\text { crisis }\end{array}$ & 11.316 & 12.875 & 2.317 & 7.827 & 0.000 \\
\cline { 2 - 7 } & $\begin{array}{c}\text { During } \\
\text { crisis }\end{array}$ & 14.191 & 3.038 & -0.542 & 2.242 & 0.518 \\
\cline { 2 - 7 } & $\begin{array}{c}\text { Post- } \\
\text { crisis }\end{array}$ & 7.897 & 4.265 & 1.314 & 3.879 & 0.000 \\
\hline
\end{tabular}

Notes: NRt is log difference of the NSE 20 Share Index, MOMt is month-on-month inflation rate, YOYt is the year-on-year inflation rate.

Table A2: Cointegration Test using ADF, PP and KPSS Tests (Intercept and Trend)

\begin{tabular}{|c|c|c|c|}
\hline \multirow{2}{*}{$\begin{array}{c}\text { Cointegrating } \\
\text { Residual }\end{array}$} & ADF test & PP Test & KPSS Test \\
\cline { 2 - 4 } & Level & Level & Level \\
\hline Rnrmom $_{t}$ & $-5.011^{* * *}$ & $-13.152^{* * *}$ & 0.075 \\
\hline Rnryoy $_{t}$ & $-5.090^{* * *}$ & $-13.398^{* * *}$ & 0.063 \\
\hline
\end{tabular}

Notes: $* * * 1 \%$ significance, $* * 5 \%$ significance, $* 10 \%$ significance (i.e., ${ }^{* * *} \mathrm{p}<0.01$, ${ }^{* *} \mathrm{p}$

$\left.<0.05,{ }^{*} \mathrm{p}<0.1\right)$. Null hypothesis under the ADF and PP tests is that the residual is nonstationary or I(1). Null hypothesis under the KPSS is that the residual is stationary. Fail to reject null hypothesis of stationarity if LM value is lower than all critical values of KPSS test. KPSS (LM) critical values are (0.216 at $1 \%$; 0.146 at 5\%; and 0.119 at $10 \%)$.

Rnrmom $_{t}$ is the cointegrating residual from regressing stock market returns on the monthon-month inflation rate, and Rnryoyt is the cointegrating residual from regressing stock market returns on the year-on-year inflation rate. 